\title{
Element Analysis of Small and even Smaller Objects by ICPMS and LA-ICPMS
}

\author{
Olga Borovinskaya, Marcel Burger, Luca Flamigni, Sabrina Gschwind, Daniel Tabersky, \\ Hao A. O. Wang, Bodo Hattendorf, Joachim Koch, and Detlef Günther
}

\begin{abstract}
Inductively coupled plasma mass spectrometry is increasingly used for non-traditional applications such as the analysis of solids at high spatial resolution when combined with laser ablation or the analysis of engineered nanoparticles. This report highlights recent projects and discusses the potentials and limitations these techniques offer. High-resolution laser ablation instrumentation allows element imaging at the $\mu \mathrm{m}$-scale and can, therefore, be applied to, e.g., the mapping of metal isotope-labeled antibodies in biological tissues. Despite these advancements, the quantitative analysis of laser-produced aerosols is still a major concern. Here, the accuracy of analysis was found to strongly depend on particle size distribution but also on the morphology and composition of particles. In order to achieve a controlled supply of nanoparticles for analysis by inductively coupled plasma mass spectrometry, a dedicated microdroplet injection system was developed and characterized. This system allows a reproducible injection of single nanoparticles together with internal standards to determine their mass and composition.
\end{abstract}

Keywords: Element imaging $\cdot$ ICPMS $\cdot$ Laser ablation $\cdot$ Nanoparticle analysis

\section{Introduction}

Analyzing small objects, for example micrometer-sized structures like biological cells, or even smaller objects such as engineered nanoparticles (NPs) puts high requirements on both quantification strategies and sensitivity of the instrumentation used. Inductively coupled plasma mass spectrometry (ICPMS) and laser ablation (LA)-ICPMS have become favored techniques capable of analyzing major, minor and trace elements of sample masses down to the attogram level. However, various fundamental investigations and instrumental developments were required to better exploit the feasibilities these techniques offer. This article summarizes recent research that addressed the transport of LAproduced aerosols and their evaporation in ICP sources, analyses of single NPs

${ }^{\star}$ Correspondence: Prof. Dr. D. Günther

ETH Zurich

Department of Chemistry

Vladimir-Prelog-Weg 1

$\mathrm{CH}-8093$ Zurich

Tel.: +4144632 4687

E-mail: guenther@inorg.chem.ethz.ch by ICPMS, high spatially resolved LAICPMS of tissue thin sections, and the development of a portable LA sampling unit.

In 1997, the design of a stationary ultraviolet (UV) nanosecond (ns) ArF excimerbased LA system conceived for the characterization of geologically relevant sample materials by ICPMS started a renaissance in the field of solid analysis. ${ }^{[1]}$ The system features a laser beam homogenization and delivery/observation assembly permitting the production of LA craters of nearly diffraction-limited size and superior morphology, which even made $\mu \mathrm{m}$-sized fluid inclusions or other subtle sample features accessible. ${ }^{[2]}$ Today, it can still be considered state-of-the-art and is being used in numerous laboratories although new generations of ns- as well as femtosecond (fs)-LA systems have been developed and enabled the range of materials that can be analyzed by ICPMS to be extended.

Despite the instrumental advancements made in ICPMS and laser technology, research has focused on the conception of optimization strategies, the promotion of guidelines of how to improve analyses in terms of precision and accuracy, and fundamental research associated with LAICPMS. In this context, the origins causing inaccuracies of LA-ICPMS analyses, often referred to as elemental fractionation, ${ }^{[3-7]}$ have been explored in several projects. LA-, aerosol transport-, and ICP-induced effects were examined. For instance, shifts in the axial position of complete evaporation for aerosols with different compositions were found to be a factor that imposes a challenge on the quantification of unknown sample material by LA-ICPMS using non-matrix matched calibration standards. However, non-matrix matched calibration is frequently the only possible approach for the analysis of minerals, ceramics, catalysts, archaeological samples, or newly synthesized materials when using LA-ICPMS. To determine the limitations of this quantification approach, fundamental studies towards the evaporation of aerosol particles have been carried out.

Some application-oriented projects dealt with the development of sampling strategies to analyze objects either too large to be hosted in conventional LA cells or even immobile. Two combined approaches applying i) a portable diodepumped solid state (DPSS) laser coupled to a handheld LA module via fiber optics and ii) a gas exchange device have been tested. New methods for the element- or isotope-specific analysis of solids were investigated. Further, due to the high spatial resolution in the micrometer range available with nearly diffraction-limited beam delivery optics, element imaging, i.e. mapping by LA-ICPMS has recently become a major application. To sufficiently shorten the analysis time imaging of larger areas requires fast and low-volume transport systems permitting to entrain aerosols as discrete pulses into the ICP and, in this way, to avoid a mixing of information at higher LA repetition rates. Such a system was designed and preliminary tests have been made.

Another research focus presented in this review is the analysis of engineered NPs by ICPMS; a strongly emerging field 
due to the need of providing alternative technologies for NP characterization in terms of composition, size, and number concentration, which, most commonly, is accomplished by optical and electron microscopic techniques. For this purpose, a compact NP delivery unit based on a microdroplet generator was built allowing for the ICPMS analysis of individual NPs by mass and main composition without a time-consuming sample preparation.

\section{Fundamental Research}

\section{LA Fundamentals}

Even though UV-ns-LA-ICPMS using both matrix- as well as non-matrix matched calibration and internal standardization has successfully been applied to the analyses of silicate glasses and minerals, the quantification of metals or semi-conductors remained problematic since the formation of the so-called heat-affected zone (HAZ) near the ablation crater gives rise to material re-distribution during the LA process. As a consequence, the total composition of aerosols formed by UV-ns-LA may considerably deviate from that of the bulk material, especially if strongly fractionating materials such as metal alloys are analyzed. In order to restrain these effects, the laser pulse duration was proposed to be reduced to values below the so-called material-specific thermal relaxation period, i.e. the time it takes to transfer the pulse energy absorbed by free electrons to the lattice ions before melting starts. ${ }^{[8,9]}$ For metals - which represent the most critical class of material in terms of HAZ formation thermal relaxation was shown to take place on a time-scale of few hundred fs. In fact, the utilization of lasers providing pulse durations in this range was found to significantly improve the LA characteristics and to get closer to the ideal concept of matrix-independent, stoichiometric LA. ${ }^{[10-13]}$ Over the last decade, fs-LA as a way to create stoichiometric aerosols has been explored with special emphasis on the inspection of collected aerosol particles by scanning electron microscopy (SEM), transmission electron microscopy (TEM), and ICPMS analyses. ${ }^{[14,15]}$ In this conjunction, fs-LA was shown to produce aerosols mainly consisting of primary nanoparticles (NP) and aggregates in the mesoscopic size range between approximately 10 and $250 \mathrm{~nm}$ that are efficiently transported over large distances and whose over-all composition is stoichiometric if the LA parameters such as wavelength, fluence, and carrier gas are adequately chosen. In Fig. 1, SEM and TEM micrographs of collected fs-LA-produced particles are shown.

Owing to the experience gathered ever since the first pilot projects were launched

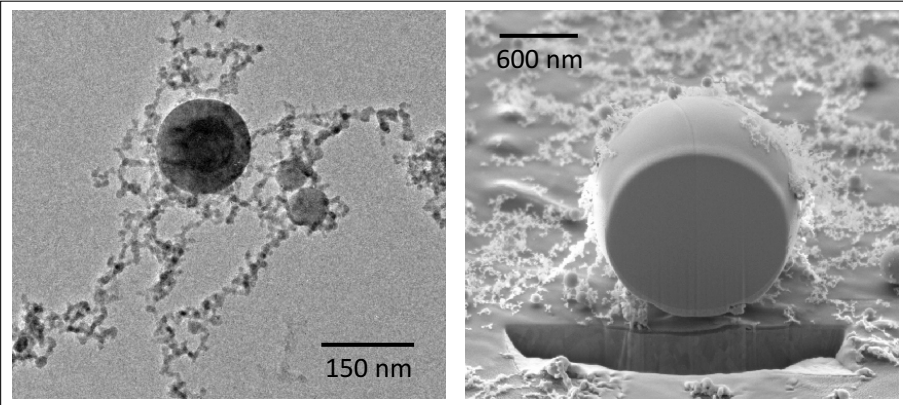

Fig. 1. Top left panel: TEM micrograph of particles produced by fs-LA of brass. Top right panel: Focused ion beam (FIB) SEM of a $\mu \mathrm{m}$-sized brass particle deposited on a TEM grid. FIB was used to study in inner structure of particles. Bottom panel: SEM

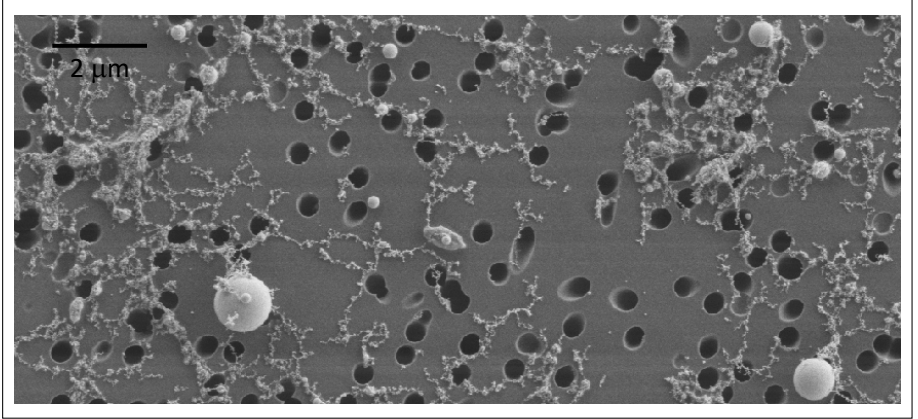
of aerosol particles produced by fs-LA of $\mathrm{Li}_{2} \mathrm{~B}_{4} \mathrm{O}_{7}$ in air.

in $2005 \mathrm{fs}-\mathrm{LA}$-ICPMS has been applied to a variety of geological and industrial tasks including, e.g., U/Pb-based geochronology or steel alloy analyses. ${ }^{[16-18]}$ At the same time, fundamental studies aiming to explore the fs-LA process with respect to particle formation, expansion, and aerosol dispersion were started to i) provide experimental input for scientific groups dealing with the theory of laser-matter interactions, ii) to explore the structure of aerosols transported to ICP sources and, thus, iii) to comprehend remaining restrictions of ICPMS analyses. For this, light scattering and shadowgraphy assemblies were installed in 2007, which enabled visualization of the LA process and subsequent transport phenomena with a temporal resolution of $<10 \mathrm{~ns}$. $^{[19-22]}$ In addition to these experimental studies, the expansion of aerosols was modeled by computational fluid dynamics (CFD).

\section{Two-dimensional (2D) OES Mapping of ICP Sources}

Over the last two years, efforts have also been made to explore material-dependent evaporation and diffusion processes of aerosols passing through ICP sources; knowledge on both processes is considered a prerequisite to identify origins of quantification errors that often occur during LAICPMS when performed on the basis of non-matrix matched calibration standards. Here, the evaporation of LA-produced aerosol particles and subsequent out-ofaxis diffusion of free atoms was investigated by $2 \mathrm{D}$ optical emission spectrometry (OES) applying interference filters as well as a Czerny-Turner monochromator ${ }^{[23,24]}$ and ICP-quadrupole (Q)MS of individual particles.[25,26] For example, $\mathrm{Na}$ - and $\mathrm{Ca}-$ specific OES of aerosols produced by LA of silicate glasses or metals revealed axial shifts in the onset and maximum position of atomic emission which occurred over a range of a few millimeters. The occurrence of these shifts was attributed to composition-dependent aerosol penetration depths, i.e. the axial points of evaporation onset, which ultimately determine radial diffusion of the ion cloud and thereby can affect the ion extraction efficiency through the ICPMS vacuum interface.

Furthermore, ICPMS analysis of individual particles resulted in signal durations of approximately one hundred microseconds, which complied with modeled values if OES maxima were assumed to coincide with positions of instantaneous evaporation and starting points of atomic diffusion. To prove observed phenomena for consistency $a b$ initio and semi-empirical simulations of aerosol penetration depths followed by diffusion-driven expansion was accomplished indicating differences of up to $15 \%$ in the relative ion extraction efficiency depending on whether analytes were supplied as metals or oxides. These findings supported our initial hypothesis that elemental fractionation due to material-dependent aerosol penetration depths cannot generally be excluded as origin of quantification errors in LA-ICPMS. In the top panel of Fig. 2, the axial emission profile of $\mathrm{Na}$ atoms along the ICP central channel originating from $\mathrm{Na}-$ and $\mathrm{Na}_{2} \mathrm{O}-$ containing aerosols is shown. Apparently, the OES maximum for $\mathrm{Na}_{2} \mathrm{O}$ particles was shifted by about $+2.5 \mathrm{~mm}$ suggesting deeper aerosol penetration, which is consistent with the assumption that metallic particles evaporate earlier, i.e. further upstream in the ICP because of their lower boiling point.

In a follow-up project a merging of 


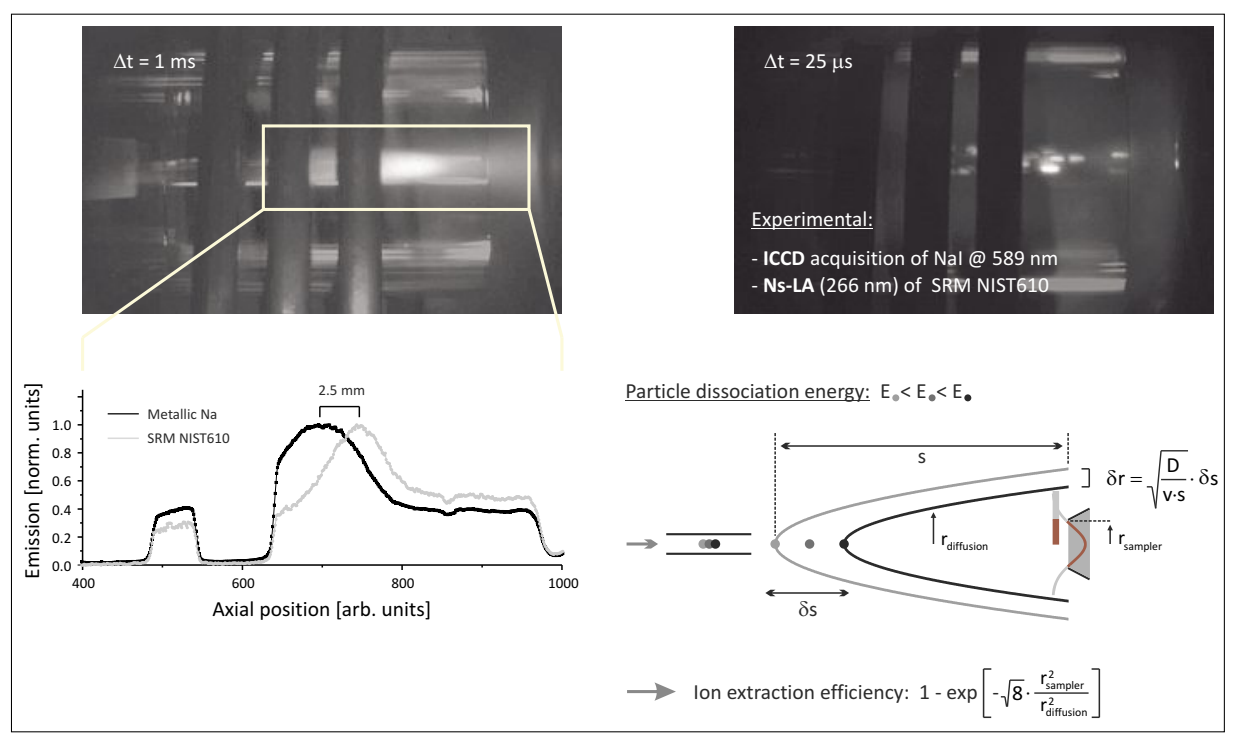

Fig. 2. Side-on 2D map of the Na-specific ICP atomic emission upon entrainment of metallic aerosols (top left) and single OES tracks of evaporating glass particles monitored when setting the camera exposure time to $25 \mu$ s (top right). In the bottom panel, 1D axial emission profiles reconstructed from a 2D OES maps captured during ns-LA of metallic and oxidic $\mathrm{Na}$ as well as a schematic illustrating out-of-axis diffusion of evaporated atoms is shown. In the latter, an expression for the ion extraction efficiency is given that assumes evaporated material forms a Gaussian distribution pattern around the axis. those shifts was achieved by adding water through a conventional nebulizer/spray chamber system attached to the aerosol transport line between LA cell and ICP injector interface. ${ }^{[27]}$ Furthermore, the utilization of a microdroplet dispenser allowed to precisely dose the amount of water entrained into the ICP and to specify the range of relative humidity required for matching the points of evaporation. Conditions specified this way were applied to quantitative LA-ICPMS analyses of silicate glass and brass using matrix matched and non-matrix matched calibration, respectively, whereby the former resulted in significant improvements of the accuracy and lower detection limits with moderate increases of the oxide formation rate.

\section{Application-oriented Research}

\section{High-speed Imaging LA-ICPMS}

The field of imaging applications in LA-ICPMS has recently benefited from the introduction of optimized transport systems. Here, sample handling and transport characteristics of current LA instruments were improved, especially with respect to spatially resolved analyses. Apart from geochemical studies, where the distribution of elements within different phases of a mineral, defined growth zones of stalagmites $^{[28,29]}$ or in individual inclusions ${ }^{[30]}$ is of interest, the biochemical field utilizes element distributions amongst different regions of a tissue section for diagnostic purposes. ${ }^{[31-33]}$ To determine the spatial distribution of elements at the sample sur- face or in depth, a reliable assignment of the ablated material to its actual position at the sample surface is required. LA cells and transport systems with optimized fluid dynamics ${ }^{[34-36]}$ are thus gaining interest.

The major advantage of such systems is a minimized aerosol dispersion allowing an increase of the acquisition speed while maintaining a clear differentiation of ICPMS signals of individual laser shots. Especially when high-resolution images shall be acquired, the LA repetition rate determines the measurement times. Therefore, conventional LA cells, where washout times of one second for a signal drop by two orders of magnitude are readily observed, would require almost two weeks of measurement in order to create an image at $1 \mu \mathrm{m}$ spatial resolution from a section of $1 \mathrm{~mm}$ by $1 \mathrm{~mm}$, i.e. $10^{6}$ points. The left panel of Fig. 3 shows an example of a LA-ICPMS analysis using a fast washout aerosol transport system ${ }^{[36]}$ and a LA repetition rate of $30 \mathrm{~Hz}$, in which signals could be fully separated reducing measurement times to 9.5 hours in this case. The system utilized a minimum dead volume LA cell fitting seamlessly into the transport tube. The configuration additionally minimized aerosol loss during transport as is indicated by slightly higher integrated ion signal intensities per peak. The right panel of Fig. 3 shows an image acquired using this set-up representing a $165 \mu \mathrm{m}$ by $165 \mu \mathrm{m}$ section of a breast cancer tissue stained by Ho-tagged antibodies that were selectively attached to the human epidermal growth factor receptor 2 , which is abundant in the cell membrane. High intensities are indicative for the cell membrane and an identification of individual cells is possible. Sub-cellular resolution can be achieved while the measurement time for the image shown was less than 30 minutes.

\section{Atmospheric Sampling LA-ICPMS}

LA sampling normally utilizes closed, airtight cells to hold the samples of interest. Ultimately, large specimen would have to be cut in smaller sections to fit into the cell, which increases sample preparation times, danger for contamination, and eventually information loss when samples need to be sawed. In these cases, precious samples like archeological artifacts or imin buildings cannot be analyzed. Thus, in order to broaden the applicability of LAICPMS to such materials as well, methods are being developed in our laboratory to allow either sampling in the field by LA-based methods or omission of closed mobile species like construction materials

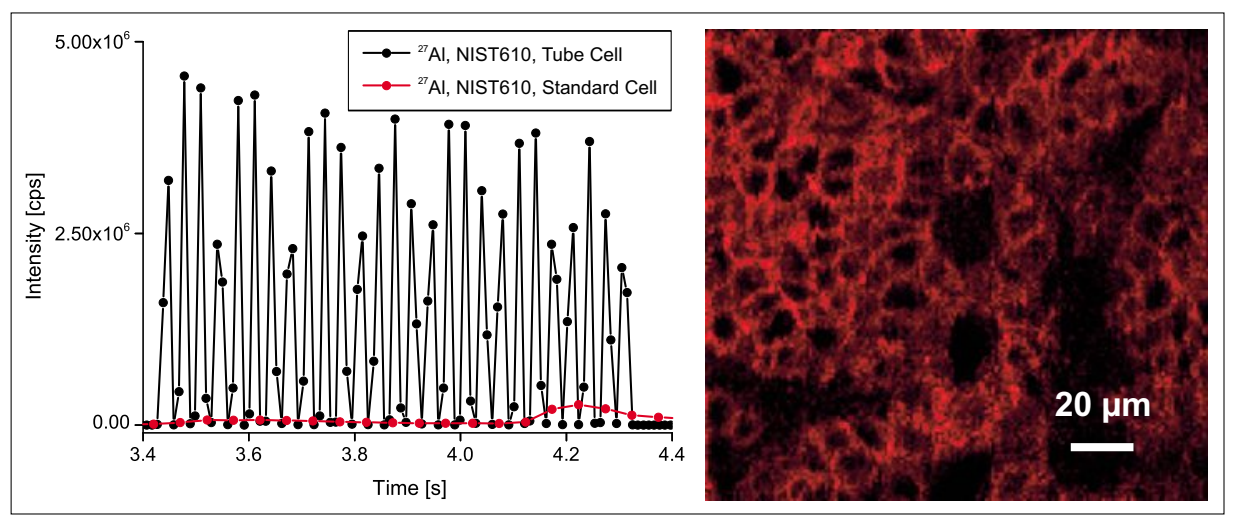

Fig. 3. Transient Al-specific ICPMS signals acquired by a conventional (red) and high-speed LA cell (black) using $30 \mathrm{~Hz}$ LA repetition rate and a single shot, respectively (left panel). Right panel: Image created from a tissue using the high-speed LA cell, $1 \mu \mathrm{m}$ spot size, and $20 \mathrm{~Hz}$ repetition rate. The transient signal shows that unambiguous assignment of the ion signal to position can be made even at high repetition rates without signal loss. Average integrated peak areas were $6 \times 10^{4}$ counts for the high-speed LA cell and $5 \times 10^{4}$ counts for the standard cell. The image was reconstructed from the ${ }^{165} \mathrm{Ho}$ intensity used to label a membrane protein. 


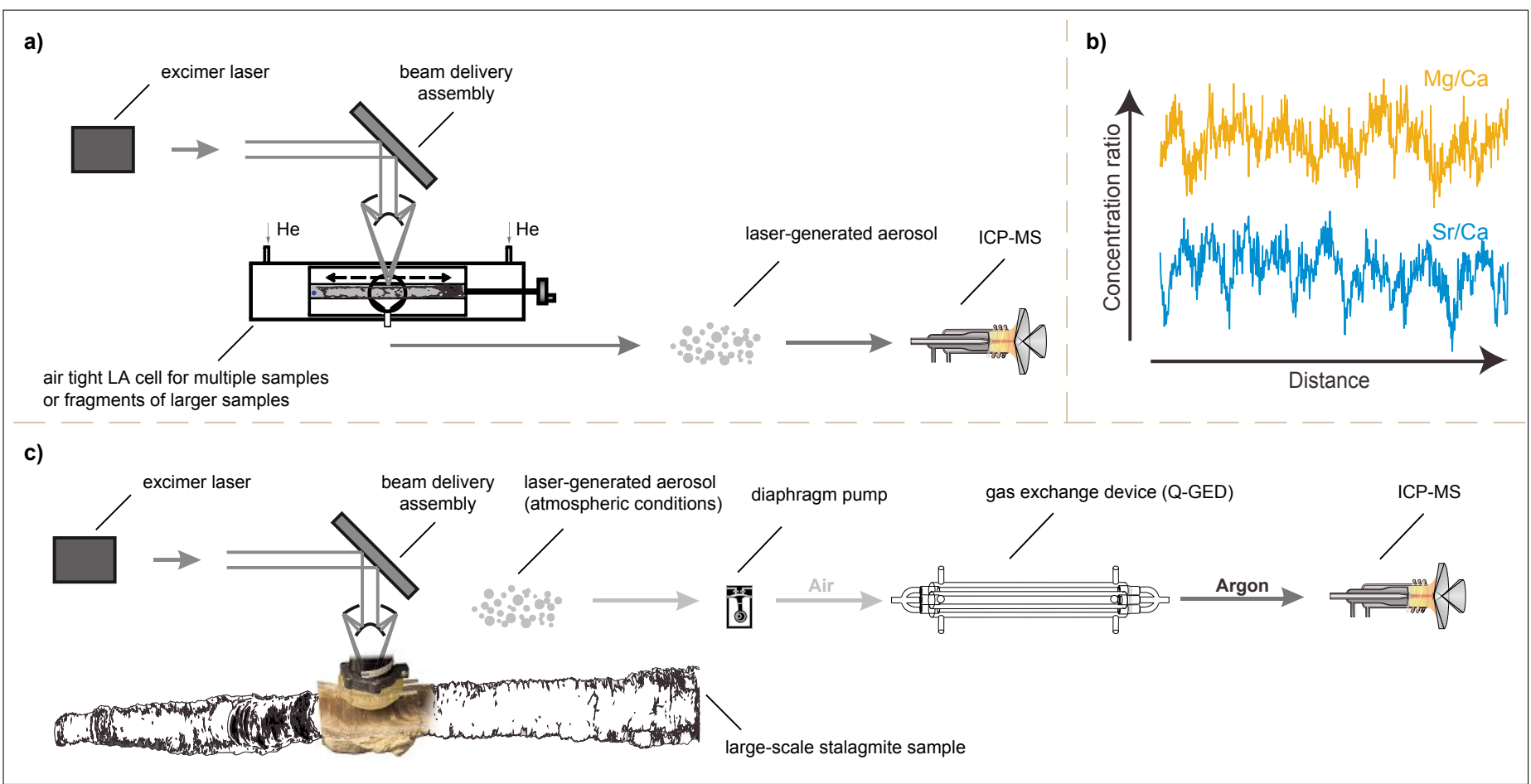

Fig. 4. Comparison of closed (a) and open (c) cell LA-ICPMS. In a) the sample is cut and placed in an airtight compartment continuously flushed with a carrier gas (helium in this case) that carries the aerosol to the ICP ion source. In c) the aerosol is extracted from the open cell system via a diaphragm pump into the gas exchange device and the ICP. The gas exchange from air to argon is required to ensure stable operation of the ICP. The insert (b) shows an example of concentration ratios obtained for a stalagmite sample with the atmospheric sampling approach, where the sample was continuously moved relative to the laser beam.

cells. ${ }^{[37-39]}$ In Fig. 4, a recent approach of sampling of LA-produced aerosols in ambient air is illustrated.

Sampling was performed using an open cell system attached only to the surface of the specimen and the aerosol was then transported in ambient air into a gas exchange device ${ }^{[40]}$ where the original carrier gas (air) was replaced by argon via diffusion through a porous silica membrane while solid aerosol particles remained in the gas stream flowing into the ion source. This exchange was necessary because the ICP source cannot be operated in a stable manner with a flow of $0.8 \mathrm{~L} / \mathrm{min}$ air as carrier gas. The LA region was partially enclosed by the open cell system in order to enhance the collection efficiency of the aerosol. Comparing open and closed LA yielded practically identical transport efficiency ${ }^{[39]}$ and indicated representative aerosol extraction. One great advantage of this configuration is that extremely large samples (up to $500 \mathrm{~mm}$ in length have been tested) can be directly analyzed while continuously scanning the laser beam across the region of interest. Conventional closed ablation cells, on the other hand, can typically host samples with dimensions not exceeding an area of $100 \times 100 \mathrm{~mm}^{2}$.

Another approach proposed ${ }^{[41]}$ is based on a portable LA system that can be used for sampling in the field. It comprises a specially designed optical and fluid dynamics system (Fig. 5) that allows ablated material to be collected on filters for posterior ICPMS analysis in the laboratory. The portable LA unit consists of a monolithic and frequency-doubled DPSS Yb:YAG la$\operatorname{ser}(\lambda=515 \mathrm{~nm})$ providing a repetition rate of up to $1 \mathrm{kHz}$ and an output energy of 1 $\mathrm{mJ} /$ pulse. The laser radiation is delivered through a $2 \mathrm{~m}$ long optical fiber to the entrance of the handheld sampler. After focusing, a spot size of $100 \mu \mathrm{m}$ with an energy density of about $5 \mathrm{~J} / \mathrm{cm}^{2}$ is obtained, which is sufficient for LA of opaque materials such as metals or ceramics. The total mass of ablated material is primarily determined by the sampling rate per pulse and number of pulses applied. Several thousand pulses can usually be applied before the aerosol collected on the filter chokes the gas flow through the sampler head and impairs its collection efficiency. The collected material can then be analyzed either directly by stationary LA methods or after mineralization by, e.g., microwave-assisted digestion. Initial tests showed that re-ablation of the material yields reliable data for a variety of samples, which would otherwise not have been accessible. The sensitivity and reproducibility ultimately depends on the amount of material sampled in the first LA step. Limits of detection in the sub-

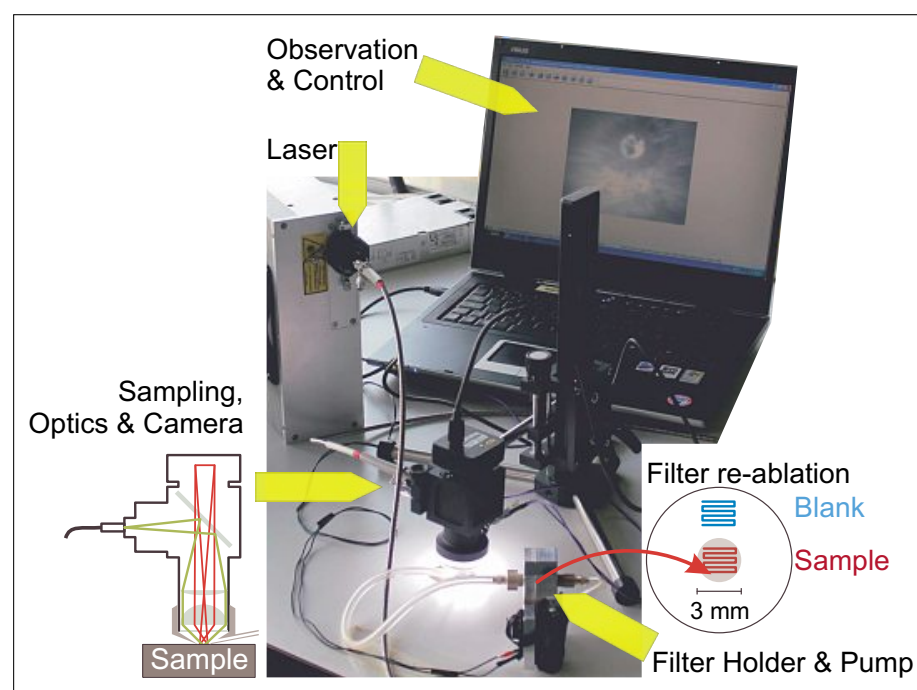

Fig. 5. View of the portable LA system for sampling in the field. The sampler (left drawing) shows the principal components and beam path for the laser light (green) and camera observation (red) of the sampler head. The right sketch explains the strategy for the laboratory-based analysis of filters. 
$\mu \mathrm{g} / \mathrm{g}$ range can be achieved but filter contamination can impose a limitation on the analysis of elements present in airborne aerosols like $\mathrm{Na}$ or $\mathrm{Ca}$. In Table 1, the concentration data obtained from the analysis of a high purity copper reference material (BAM M385) are listed. They were determined by first ablating the material using the portable system with 5000 laser pulses and subsequent LA-ICPMS of the filter-collected material. Matrix-matched calibration (BAM M376) was employed resulting in a good agreement with reference values. However, Ni and Se appeared to be significantly enriched while Fe was found too low.

\section{Delivery of NPs by Microdroplets}

Since the beginning of 2010 , the feasibilities of ICPMS for the analysis of single NPs carried by monodisperse microdroplets have been examined in our laboratories using NP delivery devices similar to that shown in Fig. 6. In the course of these studies Au- and Ag-specific detection efficiencies of about $10^{-6}$ counts per atom were achieved using quadrupole based ICPMS, while size-related limits of quantification were found to be in a range between approximately 20 and $30 \mathrm{~nm}$. ${ }^{[42]}$

Instead of argon only-based delivery systems commonly used for solution nebulization ICPMS of single NPs, ${ }^{[43-46]}$ an argon-helium mixture was chosen as carrier gas permitting droplets to be dried at ambient temperatures over transport distances of several tens of centimeters. In this set up the droplet introduction system could be mounted in a horizontal arrangement allowing convenient connection to the ICP torch of any conventional ICPMS. To shed light upon the influence of helium on the drying process the evaporation of pure, saline, and NP-containing microdroplets $\left(\varnothing_{\text {droplet }}=40-50 \mu \mathrm{m}\right)$ at ambient conditions was explored.[47] The liquid-to-gas mass transfer water droplets experience during evaporation was determined by monitoring their size in different sections of a custom-made transport system, corresponding to increasing residence times after production. Drying times specified this way turned out to be approximately three times faster than values achievable by heavier gases such as argon which is commonly chosen as carrier gas for subsequent NP analysis by ICPMS. Furthermore, residues of saline droplets doped with defined concentrations of $\mathrm{Ca}\left(\mathrm{NO}_{3}\right)_{2}$ in $1 \% \mathrm{HNO}_{3}$ were classified by light scattering (LS) and SEM indicating nearly complete desolvation over a few tens of centimeters long transport distances if helium or argon/helium mixtures were used as carrier. Mass transfer rates along droplet trajectories simulated by CFD were found to be in agreement with measured ones and proved
Table 1. Concentration data obtained from the analysis of a high purity copper (BAM M385) using a portable LA system for sampling and subsequent LA-ICPMS of the filter-collected material.

\begin{tabular}{|l|c|c|c|}
\hline Element & $\begin{array}{c}\text { Measured conc. } \\
{[\mu \mathrm{g} / \mathrm{g}]}\end{array}$ & $\begin{array}{c}\text { Reference conc. } \\
{[\mu \mathrm{g} / \mathrm{g}]}\end{array}$ & $\begin{array}{c}\text { Recovery } \\
{[\%]}\end{array}$ \\
\hline $\mathrm{Mn}$ & $10.1 \pm 0.1$ & $10.1 \pm 0.2$ & 99 \\
\hline $\mathrm{Fe}$ & $31.2 \pm 0.2$ & $45.4 \pm 1.4$ & 69 \\
\hline $\mathrm{Co}$ & $7.1 \pm 0.11$ & $6.9 \pm 0.2$ & 102 \\
\hline $\mathrm{Ni}$ & $(21)$ & $11.9 \pm 0.8$ & 176 \\
\hline $\mathrm{Zn}$ & $58.2 \pm 0.2$ & $58 \pm 4$ & 100 \\
\hline $\mathrm{As}$ & $10.8 \pm 0.3$ & $11.4 \pm 0.8$ & 95 \\
\hline $\mathrm{Se}$ & $9.8 \pm 0.1$ & $7.2 \pm 0.5$ & 136 \\
\hline $\mathrm{Ag}$ & $27.3 \pm 0.1$ & $28.6 \pm 0.8$ & 96 \\
\hline $\mathrm{Cd}$ & $5.2 \pm 0.7$ & $5.8 \pm 0.3$ & 90 \\
\hline $\mathrm{Sn}$ & $17.4 \pm 0.2$ & $18.0 \pm 0.9$ & 95 \\
\hline $\mathrm{Sb}$ & $19.6 \pm 0.2$ & $19.1 \pm 0.8$ & 103 \\
\hline $\mathrm{Te}$ & $10.9 \pm 0.2$ & $10.0 \pm 0.4$ & 109 \\
\hline $\mathrm{Pb}$ & $11.7 \pm 0.1$ & $11.3 \pm 0.5$ & 103 \\
\hline $\mathrm{Bi}$ & $5.9 \pm 0.1$ & $5.8 \pm 0.2$ & 102 \\
\hline
\end{tabular}

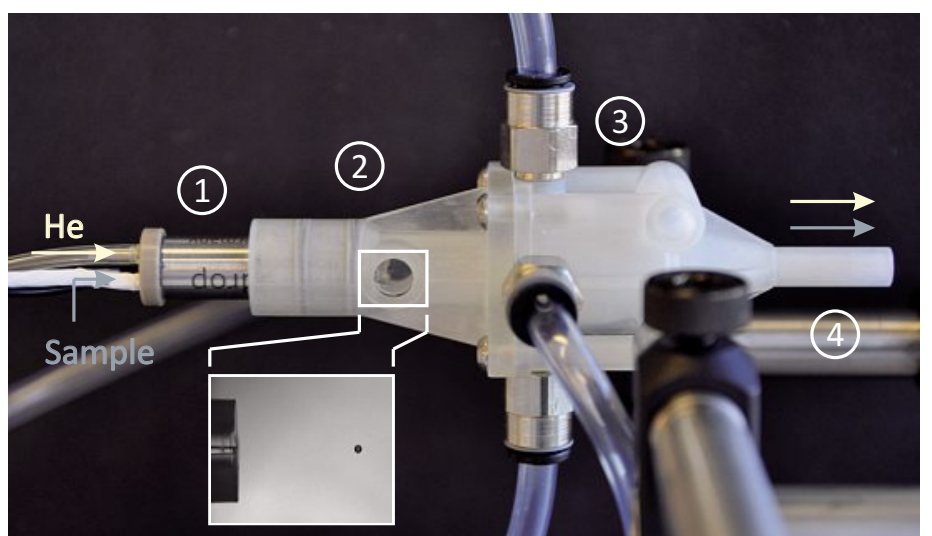

Fig. 6. Picture of a horizontally arranged NP delivery device consisting of a microdroplet dispenser (1), observation window (2), main compartment which, in this case, was equipped with four Ar ports (3), and outlet (4). Both NP suspensions and He were supplied through the dispenser.
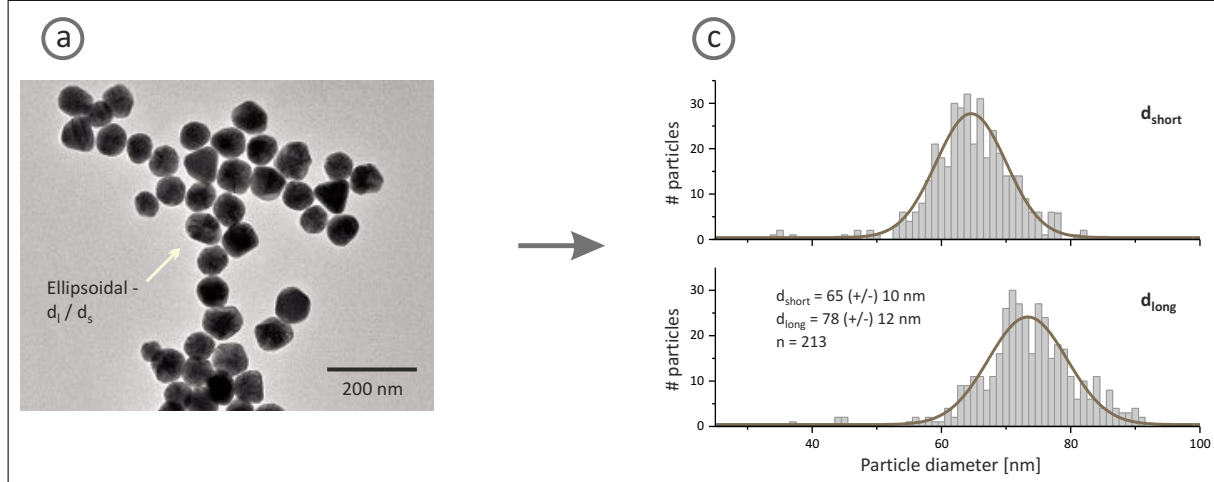

(b) (d)
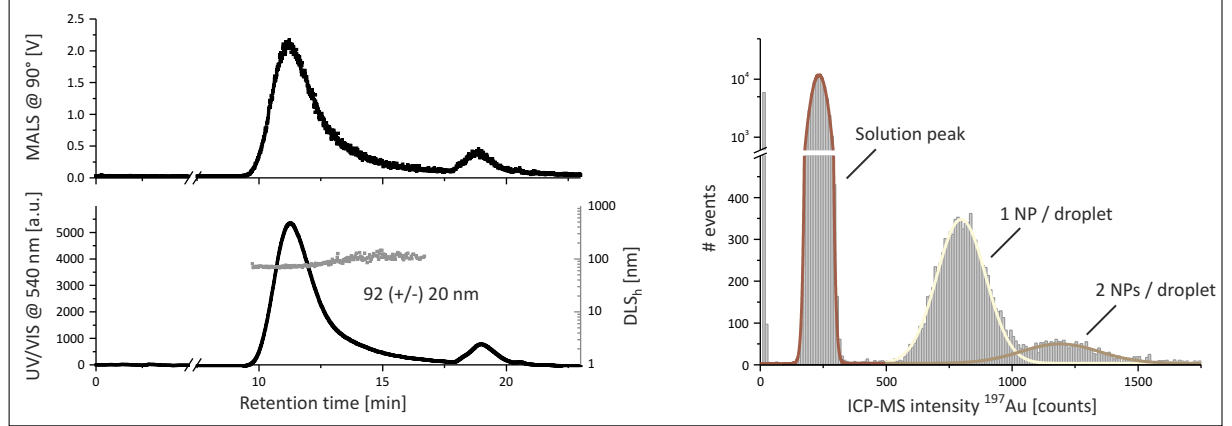

Fig. 7. Intensity vs. frequency histograms compiled from ICPQMS Au NPs applying microdroplet delivery and morphology inspection or sizing done by complementary techniques TEM and A4F linked with DLS and MALS, respectively. 
the applicability of the evaporation model used. We, thus, suggested making use of such models as alternatives for a timeconsuming adaptation by trial-and-error whenever user-defined transport systems have to be designed. The analytical capabilities of helium-assisted evaporation $v s$. common approaches employing argon only based set-ups operated at increased temperatures were, in addition, demonstrated by ICP quadrupole (Q)MS of Au NPs. ${ }^{[42,48]}$ Therefore, NP-containing droplets were delivered through a horizontally arranged transport assembly, as shown in Fig. 6, and resulted in a throughput of nearly $100 \%$. In the bottom right panel (d) of Fig. 7, an intensity $v s$. frequency histogram compiled from ICPQMS of a monodisperse $\mathrm{Au}$ NP suspension applying microdroplet delivery is shown; morphology inspection or sizing accomplished by the complementary techniques TEM and asymmetric flow field-flow fractionation (A4F) coupled with dynamic light scattering (DLS) and multi-angle light scattering (MALS) are illustrated in panels (a)-(c).

Although our findings demonstrated the advantages that helium offers as a drying agent for ICPMS analyses of droplet-delivered NPs over other heavier carrier gases such as argon we pointed out that buoyant forces which always occur whenever gases of different density are supplied must be accounted for when designing transport assemblies. For instance, the formation of even slightly asymmetric or complex flow patterns due to the admixture of argon too far upstream gave rise to a higher temporal jitter in the over-all transit time of droplets or provoked turbulences which occasionally resulted in the settling of droplets inside the transport system. If, however, care is taken to counterbalance buoyant and gravitational forces, a shortening of vertical systems can be achieved and even horizontal droplet delivery through compact devices becomes possible. Based on the droplet delivery system proposed here various batches of NP suspension have been analyzed using an in-house built ICP time of flight (TOF)MS ${ }^{49]}$ that allows complete spectra to be acquired with a frequency of up to $30 \mathrm{kHz}$ corresponding to a temporal resolution of about $30 \mu \mathrm{s}$. In contrast to analyses by sequential detection as done in QMS or single collector sector field (SF) MS the composition of individual NPs can be unambiguously assigned at high rates. It is, thus, possible to accomplish internal standardization based on dissolved salts to quantify NPs and to monitor instrumental drifts over time. Additionally, the high acquisition rate made it possible to elucidate the influence of NP trajectories inside the ICP on the residence times of individual elements for the first time. It was observed that elements present in the same micro- droplet or single LA-produced particles showed notable differences in their transient profiles, which can only explained by fractionated evaporation in combination with a velocity gradient inside the ICP ion source. ${ }^{[50]}$

\section{Summary}

In this paper, instrumental as well as methodical advancements related to high spatially and temporally resolved of main, minor, and trace element analyses or isotope ratio determinations by ICPMS and LA-ICPMS were reviewed. Furthermore, fundamental studies addressing, e.g., the 2D imaging of ICP sources by OES as a diagnostic tool to examine the evaporation process of LA-produced aerosols were reported. 1D axial profiles reconstructed from 2D OES maps indicated composition-dependent aerosol penetration depths, i.e. shifts in the axial positions of early evaporation, which defines the onset of radial diffusion thereby affecting the ion extraction efficiency and, thus, accuracy of LA-ICPMS analyses. The simultaneous addition of water was found to be one possible strategy that allows penetration depths to be merged and to improve the accuracy without changing standard ICPMS settings drastically. Future studies dealing with an adaptation of ICPMS power and gas flow settings or the development of a new torch design might also help to overcome some of the remaining shortcomings.

A newly developed tube-cell allowed the transport of discrete aerosol packages and rendered LA-ICPMS of, e.g., tissue-thin sections at LA repetition rates of 20 to $30 \mathrm{~Hz}$, corresponding to an overall washout time of $30 \mathrm{~ms}$. In this way, a faster acquisition of element maps with a maximum spatial resolution of $1 \mu \mathrm{m}$ became possible without the use of potentially error-prone signal de-convolution algorithms. However, a five times faster washout would be needed to reduce measurement times imaging areas larger than about $1 \mathrm{~mm}$ by $1 \mathrm{~mm}$ below one hour.

The use of a portable LA unit was shown to enable the sampling of objects outside the laboratory for off-line quantification. In particular, the analysis of paints, paint layers, stones and other artifacts in the field is becoming possible and the limits of detection were found to be one to two orders of magnitude below those offered by other portable techniques, such as $\mathrm{X}$-ray fluorescence (XRF) or laser-induced breakdown spectrometry (LIBS). Another atmospheric laboratory-based LA sampling strategy described here makes use of a gas exchange device capable of completely exchanging ambient air by noble gases required for in-line ICPMS analyses while keeping aerosol losses minimum. This approach provides major advantages when compared to closed LA cells commonly used since samples of different sizes and geometries can be analyzed; an important aspect for analyses of precious objects such as archaeological artifacts which cannot be cut in pieces.

Quantitative analyses of NPs by mass, size, and number concentration using ICPMS are becoming a future challenge mainly due to the sensitivity offered by current instruments which do not yet permit NPs smaller than about $15 \mathrm{~nm}$ to be analyzed. Furthermore, NPs are commonly supplied by solution nebulization which is straightforward but holds the risk of quantification errors if no standard suspensions are available or NP transport efficiencies are unknown. Here, a delivery of individual NPs by microdroplets was proposed which allowed achieving transport efficiencies of almost $100 \%$ and, in addition, rendered quantification by internal standardization possible. NP-containing microdroplets were supplied through a compact adaptor directly attached to the ICP injector tube interface and using $\mathrm{He}$ as drying agent. First ICPMS analyses of $\mathrm{Au}$ and Ag NP suspensions were promising and indicated the device to be fit-for-purpose. Efforts to optimize the adaptor's design are ongoing and are accompanied by the development of an ultrafast ICPTOFMS enabling the analysis of complex NP mixtures.

Received: January 28, 2014

[1] D. Günther, R. Frischknecht, C. A. Heinrich, H. J. Kahlert, J. Anal. At. Spectrom. 1997, 12, 939.

[2] D. Günther, A. Audetat, R. Frischknecht, C. A. Heinrich, J. Anal. At. Spectrom. 1998, 13, 263.

[3] D. Günther, B. Hattendorf, TRAC-Trend. Anal. Chem. 2005, 24, 255.

[4] P. M. Outridge, W. Doherty, D. C. Gregoire, Spectrochim. Acta B 1997, 52, 2093.

[5] P. M. Outridge, W. Doherty, D. C. Gregoire, Spectrochim. Acta B 1996, 51, 1451

[6] B. J. Fryer, S. E. Jackson, H. P. Longerich, Can. Mineral. 1995, 33, 303

[7] R. E. Russo, X. L. Mao, O. V. Borisov, H. C. Liu, J. Anal. At. Spectrom. 2000, 15, 1115.

[8] S. Nolte, C. Momma, H. Jacobs, A. Tunnermann, B. N. Chichkov, B. Wellegehausen, H. Welling, J. Opt. Soc. Am. B 1997, 14, 2716

[9] B. N. Chichkov, C. Momma, S. Nolte, F. Vonalvensleben, A. Tünnermann, Appl. Phys. A 1996, 63, 109.

[10] J. Koch, H. Lindner, A. von Bohlen, R. Hergenröder, K. Niemax, J. Anal. At. Spectrom. 2005, 20, 901 .

[11] J. Koch, A. von Bohlen, R. Hergenröder, K. Niemax, J. Anal. At. Spectrom. 2004, 19, 267.

[12] C. Y. Liu, X. L. Mao, S. S. Mao, R. Greif, R. E. Russo, Anal. Chem. 2005, 77, 6687.

[13] C. Y. Liu, X. L. Mao, J. Gonzalez, R. E. Russo, J. Anal. At. Spectrom. 2005, 20, 200.

[14] R. Glaus, R. Kaegi, F. Krumeich, D. Günther, Spectrochim. Acta B 2010, 65, 812 .

[15] M. Wälle, J. Koch, D. Günther, J. Anal. At. Spectrom. 2008, 23, 1285.

[16] H. Wiltsche, D. Günther, Anal. Bioanal. Chem. 2011, 399, 2167. 
[17] B. K. Kuhn, K. Birbaum, Y. Luo, D. Günther, J. Anal. At. Spectrom. 2010, 25, 21.

[18] H. L. Yuan, S. Gao, M. N. Dai, C. L. Zong, D. Günther, G. H. Fontaine, X. M. Liu, C. Diwu, Chem. Geol. 2008, 247, 100.

[19] S. Heiroth, J. Koch, T. Lippert, A. Wokaun, D. Günther, F. Garrelie, M. Guillermin, J. Appl. Phys. 2010, 107, 014908.

[20] J. Koch, M. Wälle, R. Dietiker, D. Günther, Anal. Chem. 2008, 80, 915 .

[21] J. Koch, M. Wälle, S. Schlamp, T. Rösgen, D. Günther, Spectrochim. Acta B 2008, 63, 37.

[22] J. Koch, S. Schlamp, T. Rösgen, D. Fliegel, D. Günther, Spectrochim. Acta B 2007, 62, 20.

[23] J. W. Olesik, G. M. Hieftje, Anal. Chem. 1985, 57, 2049.

[24] S. E. Hobbs, J. W. Olesik, Spectrochim. Acta B 1997, 52, 353.

[25] L. Flamigni, J. Koch, D. Günther, Spectrochim. Acta B 2012, 76, 70 .

[26] L. Flamigni, J. Koch, H. Wiltsche, R. Brogioli, S. Gschwind, D. Günther, J. Anal. At. Spectrom. 2012, 27, 619 .

[27] L. Flamigni, J. Koch, D. Günther, J. Anal. At. Spectrom. 2014, DOI: 10.1039/C3JA50314C.

[28] R. N. Drysdale, B. T. Paul, J. C. Hellstrom, I. Couchoud, A. Greig, P. Bajo, G. Zanchetta, I. Isola, C. Spotl, I. Baneschi, E. Regattieri, J. D. Woodhead, Quaternary Geochronology 2012, 14,38 .
[29] K. P. Jochum, D. Scholz, B. Stoll, U. Weis, S. A. Wilson, Q. C. Yang, A. Schwalb, N. Borner, D. E. Jacob, M. O. Andreae, Chem. Geol. 2012, 318,31 .

[30] T. Ulrich, D. Günther, C. A. Heinrich, Nature 1999, 399, 676.

[31] J. Seuma, J. Bunch, A. Cox, C. McLeod, J. Bell, C. Murray, Proteomics 2008, 8, 3775.

[32] D. Drescher, C. Giesen, H. Traub, U. Panne, J. Kneipp, N. Jakubowski, Anal. Chem. 2012, 84 , 9684.

[33] J. S. Becker, A. Matusch, C. Depboylu, J. Dobrowolska, M. V. Zoriy, Anal. Chem. 2007, 79, 6074.

[34] W. Müller, M. Shelley, P. Miller, S. Broude, J. Anal. At. Spectrom. 2009, 24, 209.

[35] M. B. Fricker, D. Kutscher, B. Aeschlimann, J. Frommer, R. Dietiker, J. Bettmer, D. Günther, Int. J. Mass Spectrom. 2011, 307, 39.

[36] H. A. O. Wang, D. Grolimund, C. Giesen, C. N. Borca, J. R. H. Shaw-Stewart, B. Bodenmiller, D. Günther, Anal. Chem. 2013, 85, 10107.

[37] D. Asogan, B. L. Sharp, C. J. P. O'Connor, D. A. Green, R. W. Hutchinson, J. Anal. At. Spectrom. 2009, 24, 917.

[38] R. Kovacs, K. Nishiguchi, K. Utani, D. Günther, J. Anal. At. Spectrom. 2010, 25, 142.

[39] D. Tabersky, K. Nishiguchi, K. Utani, M. Ohata, R. Dietiker, M. B. Fricker, I. M. de Maddalena, J. Koch, D. Günther, J. Anal. At. Spectrom. 2013, 28, 831 .
[40] K. Nishiguchi, K. Utani, E. Fujimori, J. Anal. At. Spectrom. 2008, 23, 1125.

[41] R. Glaus, J. Koch, D. Günther, Anal. Chem. 2012, 84,5358

[42] S. Gschwind, L. Flamigni, J. Koch, O. Borovinskaya, S. Groh, K. Niemax, D. Günther, J. Anal. At. Spectrom. 2011, 26, 1166.

[43] C. Degueldre, P. Y. Favarger, Coll. Surf. A 2003, 217, 137.

[44] C. Degueldre, P. Y. Favarger, Talanta 2004, 62, 1051.

[45] B. Franze, I. Strenge, C. Engelhard, J. Anal. At. Spectrom. 2012, 27, 1074

[46] J. W. Olesik, P. J. Gray, J. Anal. At. Spectrom. 2012, 27, 1143 .

[47] J. Koch, L. Flamigni, S. Gschwind, S. Allner, H. Longerich, D. Günther, J. Anal. At. Spectrom. 2013, 28, 1707 .

[48] S. Gschwind, H. Hagendorfer, D. A. Frick, D. Günther, Anal. Chem. 2013, 85, 5875.

[49] O. Borovinskaya, B. Hattendorf, M. Tanner, S. Gschwind, D. Günther, J. Anal. At. Spectrom. 2013, 28, 226.

[50] O. Borovinskaya, M. Aghaei, L. Flamigni, B. Hattendorf, M. Tanner, A. Bogaerts, D. Günther, J. Anal. At. Spectrom. 2014, 29, 262. 